\title{
Inhibition of Formation of Azoxymethane-induced Colonic Aberrant Crypt Foci in Rats by Edible Green Algae Capsosiphon fulvescens and Brown Algae Hizikia fusiforme
}

\author{
YOUNG-SOOK SON, H.M. ARIF ULLAH, AHMED K. ELFADL, SOONG-GU GHIM, MYUNG-JIN CHUNG, \\ YONG DEUK KIM, EUN-JOO LEE, KYUNG-KU KANG and KYU-SHIK JEONG \\ College of Veterinary Medicine and Stem Cell Therapeutic Research Institute, \\ Kyungpook National University, Daegu, Republic of Korea
}

\begin{abstract}
Capsosiphon fulvescens (green seaweed) and Hizikia fusiforme (brown seaweed) are marine algae consumed as food supplements, especially in Japan, China and Korea, and are considered traditional medicinal tonics for certain ailments. The aim of this study was to investigate the possible inhibitory effects of dietary $C$. fulvescens and $H$. fusiforme on azoxymethane (AOM)-induced colorectal cancer $(C R C)$ in rats. $F 344$ male rats (5 weeks, $150 \mathrm{~g}$ ) were divided into six groups as follows. Group 1: Injected with normal saline solution and fed control diet (untreated control). Group 2: Injected with AOM and fed control diet (treated control). Group 3: Injected with AOM and fed 1\% C. fulvescens diet. Group 4: Injected with AOM and fed $2 \%$ C. fulvescens diet. Group 5: Injected with AOM and fed $2 \%$ H. fusiforme diet. Group 6: Injected with AOM and fed 6\% $H$. fusiforme diet. Test animals received subcutaneous injections of AOM (15 mg/l ml/kg body weight) once a week for 2 weeks to induce aberrant crypt foci ( $A C F)$ in treated control and experimental groups. We evaluated the effects of dietary $C$. fulvescens and $H$. fusiforme at two different dose levels: 1 and $2 \% \mathrm{C}$. fulvescens, and 2 and $6 \% \mathrm{H}$. fusiforme, on colonic carcinogenesis by AOM in rats. Our results suggest that body weights were not significantly different amongst groups. We found that feeding $C$. fulvescens and $H$. fusiforme with a control diet significantly $(p<0.05)$ inhibited the development of ACF in experimental groups. $C$.
\end{abstract}

This article is freely accessible online.

Correspondence to: Professor, Kyu-Shik Jeong, DVM, Ph.D., College of Veterinary Medicine, Kyungpook National University, Daegu City 41566, Republic of Korea. Tel: +82 539505975, Fax: +82 539505955, e-mail: jeongks@knu.ac.kr

Key Words: Azoxymethane, colorectal cancer, Capsosiphon fulvescens, Hizikia fusiforme, rat. fulvescens and $H$. fusiforme in food also significantly $(p<0.05)$ reduced the proliferating cell nuclear antigen labeling index in the colonic tissues of experimental groups. These results demonstrate the chemopreventive potential of $C$. fulvescens and H. fusiforme against CRC in an AOMinduced rats.

Colorectal cancer (CRC) is the most common cancer, and a significant cause of death, in developed countries, including the United States $(1,2)$. Numerous factors including age, physical activity habits, environment, obesity, diabetes, diet, lifestyle, and genetics play important roles in CRC carcinogenesis $(3,4)$. Many genetic defects/mutations, including the adenomatous polyposis coli $(A P C)$ gene, kirsten ras (KRAS) oncogene, phosphatidylinositol-4,5bisphosphate 3-kinase catalytic subunit alpha (PIK3CA) gene, phosphatase and tensin homolog (PTEN) gene, transforming growth factor (TGF $\beta$ ) receptor, and tumor protein p53 (TP53) gene, and enzymes such as cyclooxygenase-2 and nitric oxide synthase have been suggested to play vital roles in CRC carcinogenesis (4-6). It is recognized that CRC develops sequentially from polyp to adenocarcinoma. This development may take a long time, as much as 10-17 years (4).

Azoxymethane (AOM) is a tumor-initiating chemical agent commonly used in models of colon cancer (7). Specifically, it can induce the formation of aberrant crypt foci (ACF) by epithelial cells, which then progress to adenomas and malignant adenocarcinomas, that is similar to the pathogenesis of sporadic human colon cancer $(8,9)$. Thus, it has been extensively used in the study of molecular biology, prevention, and treatment of colon cancer.

$\mathrm{ACF}$ are clusters of abnormal tube-like glands on the colonic mucosal surface, and are the earliest morphological changes after treatment with chemical carcinogens such as AOM (10). Evidence strongly suggests that ACF are pre-neoplastic lesions in the colon, and they are recognized as intermediate biomarkers 
of CRC in both rodents and humans $(6,11)$. Chemicallyinduced $\mathrm{ACF}$ in rodents have been used to assess new chemopreventives and diets that might prevent CRC (12).

Capsosiphon fulvescens is a green marine alga consumed as a food supplement, and is considered to possess medicinal activity and high nutritional value (13). Hizikia fusiforme is a brown marine alga, traditionally used as a foodstuff and medicine in Asia (14). Previous research reported that $C$. fulvescens and $H$. fusiforme exhibited beneficial medicinal activities, such as antioxidant, anti-diabetic, and antitumor effects (15).

The purpose of the present study was to identify the possible inhibitory effect on colon carcinogenesis of feeding $C$. fulvescens and $H$. fusiforme at different dose levels to F344 male rats. We investigated the effects of $C$. fulvescens at 1 and $2 \%$, and $H$. fusiforme at 2 and $6 \%$ dose levels in the rats' diet. In addition, we immunohistochemically analyzed the expression of proliferating cell nuclear antigen (PCNA), which plays a vital role in carcinogenesis.

\section{Materials and Methods}

Chemicals. All chemicals were of the highest grade and were purchased from commercial suppliers. AOM was purchased from Sigma Chemical Co. (St. Louis, MO, USA). Analytical-grade ethyl ether was purchased from Duksan Pure Chemicals (Ansan, Korea).

Plant materials and diets. $C$. fulvescens and $H$. fusiforme were collected from Jeonnam, Wando, South Korea, and were washed with water and dried. The seaweeds were cut into small pieces and extracted with $95 \%$ ethanol at $80^{\circ} \mathrm{C}$ for $2 \mathrm{~h}$ at $120 \mathrm{rpm}$, with ethanol at a ratio of $40 \mathrm{ml} / \mathrm{g}$. The extract was centrifuged $(8,000 \times \mathrm{g}, 10$ min), filtered, and concentrated at $60^{\circ} \mathrm{C}$. The experimental diets were prepared by adding $5 \%$ brix concentrate to AIN-76A animal diet (ORIENT BIO Inc, Sangdaewon-Dong, Seongnam-si, South Korea) (Table I) with 1 or $2 \%$ of $C$. fulvescens and 2 or $6 \%$ of $H$. fusiforme by dry weight (Table II).

Animals. F344 male rats (5 weeks, $150 \mathrm{~g}$ ) were used in these experiments (Orient Co Ltd, Seoul, Korea) and maintained in an environment with controlled temperature $\left(23 \pm 2^{\circ} \mathrm{C}\right)$ and humidity $(55 \pm 7 \%)$ under a $12 \mathrm{~h}$ light-dark cycle. All animal experiments were carried out in accordance with the National Institute of Health guidelines.

Experimental design. The rats were divided into six groups for experimental procedures as follows. In group 1 (untreated control), saline was injected $(1 \mathrm{ml} / \mathrm{kg})$ subcutaneously $(s c$.) during the first and second weeks of the experimental period. In group 2 (treated control), AOM was injected $(15 \mathrm{mg} / 1 \mathrm{ml} / \mathrm{kg}) \mathrm{sc}$. once a week for 2 weeks. The animals in both these groups were fed the control diet throughout for 11 weeks. Groups 3, 4, 5, and 6 (experimental groups) were fed experimental diets containing 1 or $2 \%$ C. fulvescens or 2 or $6 \% \mathrm{H}$. fusiforme, respectively, for 8 weeks from the third week after the administration of AOM. While group 1 had eight rats, all other groups comprised 10. Body weights and food intake of the animals were measured throughout the
Table I. AIN-76A animal diet for controls and experimental groups.

\begin{tabular}{lcc}
\hline Ingredients & $\mathrm{g} \%$ & $\mathrm{kcal} \%$ \\
\hline Casein. 30 mesh & 200 & 800 \\
DL-Methionine & 3 & 12 \\
Corn starch & 150 & 600 \\
Sucrose & 500 & 2000 \\
Cellulose, BW200 & 50 & 0 \\
Corn oil & 50 & 450 \\
Mineral mix S10001 & 35 & 0 \\
Vitamin mix V10001 & 10 & 40 \\
Choline bitartrate & 2 & 0 \\
Total & 1000 & 3902 \\
\hline
\end{tabular}

Table II. Experimental animals.

\begin{tabular}{lcc}
\hline Group & Treatment & No. of animals \\
\hline 1 & Saline + control diet & 8 \\
2 & AOM + control diet & 10 \\
3 & $\mathrm{AOM}+1 \%$ Capsosiphon fulvescens diet & 10 \\
4 & $\mathrm{AOM}+2 \%$ C. fulvescens diet & 10 \\
5 & $\mathrm{AOM}+2 \%$ Hizikia fusiforme diet & 10 \\
6 & $\mathrm{AOM}+6 \%$ H. fusiforme diet & 10 \\
\hline
\end{tabular}

AOM: Azoxymethane $15 \mathrm{mg} / \mathrm{kg}$, subcutaneous injection $(1 \mathrm{ml} / \mathrm{kg})$.

experiment. After 11 weeks, all animals were sacrificed for histopathological examination of colonic tissues (Figure 1).

Histopathological examination of colonic tumor tissues. Animals were sacrificed and colonic tumor tissues were removed immediately. The tissues were washed with normal saline and fixed in $10 \%$ neutral formalin solution $(\mathrm{pH} \mathrm{7.0)}$ ). After routine paraffin embedding, 6-8 $\mu \mathrm{m}$ tissue sections were cut, fixed on microscope slides, and deparaffinized, before being hydrated. Finally, sections were stained with hematoxylin and eosin (H\&E) for histological examination of colonic cancer specimens.

Determination of ACF. The development of carcinoma was suggested by the detection of ACF, believed to be precancerous lesions, in colonic mucosa. Rectal crypt foci were excised, and the colon was spread, washed with potassium phosphate buffer $(0.1 \mathrm{M}$, $\mathrm{pH}$ 7.2), and then fixed in $10 \%$ neutral formalin. After fixation and staining with $2.5 \%$ methylene blue, ACF were distinguished morphologically by their elliptical shape and increased size of crypts compared to normal crypts and measured microscopically.

Immunohistochemical evaluation. PCNA immunohistochemistry was performed to evaluate the proliferation of tumor cells. Paraffinembedded colonic tumor tissues cut into 6-8 $\mu \mathrm{m}$ sections. These were then immersed in xylene solution to remove paraffin and rehydrate the tissues while sequentially reducing the ethanol concentration. The slides prepared in this manner were coated with mouse monoclonal antibody against PCNA (Santa Cruz Biotechnology, Santa Cruz, CA, USA), then coated with avidin-biotin peroxidase complex (Zymed 


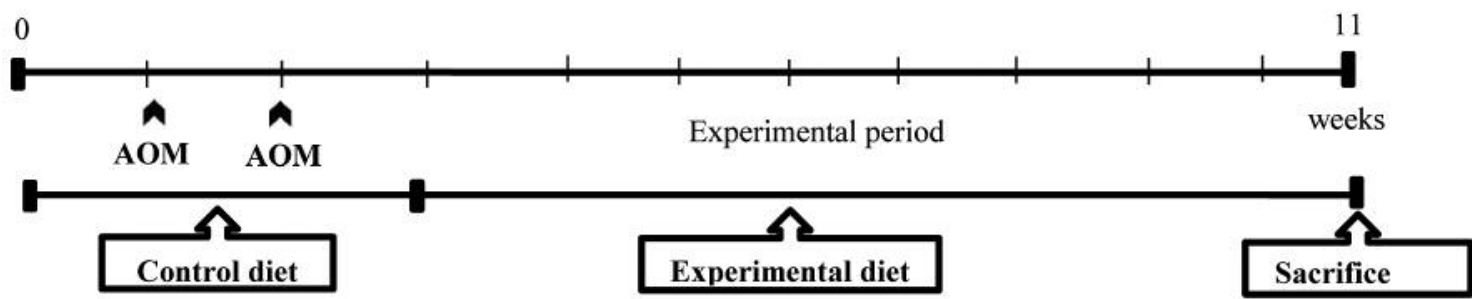

Figure 1. Experimental protocol to evaluate chemopreventive activity in F344 rats. Rats were divided into two control (untreated and treated) groups and four experimental groups. The rats were fed a control diet (AIN-76A) or diet supplemented with different doses of Capsosiphon fulvescens ( 1 or $2 \%$ ) and Hizikia fusiforme ( 2 or 6\%), for the 11-week experimental period. Rats in groups 2-6 received subcutaneous injections of azoxymethane (AOM; $15 \mathrm{mg} / \mathrm{kg}$ body weight) once a week for 2 weeks. Group 1 served as an untreated control $(1 \mathrm{ml}$ saline/kg by subcutaneous injection + control diet) and group 2 served as the treated control (15 mg AOM/kg body weight by subcutaneous injection + control diet).

Table III. Weight gain and feed intake.

\begin{tabular}{lcccc}
\hline Group & Treatment & $\begin{array}{c}\text { Body weight at start } \\
\text { of treatment }(\mathrm{g})\end{array}$ & $\begin{array}{c}\text { Body weight at } \\
\text { termination }(\mathrm{g})\end{array}$ & $\begin{array}{c}\text { Feed intake } \\
(\mathrm{g} / \mathrm{day})\end{array}$ \\
\hline 1 & Saline + control diet & $285.56 \pm 5.7$ & $340.14 \pm 6.7$ & 13.17 \\
2 & $\mathrm{AOM}+$ control diet & $268.41 \pm 5.4$ & $323.94 \pm 4.9$ & 13.35 \\
3 & $\mathrm{AOM}+1 \%$ Capsosiphon fulvescens diet & $256.05 \pm 4.8$ & $314.44 \pm 3.4$ & 14.16 \\
4 & $\mathrm{AOM}+2 \%$ C. fulvescens diet & $243.17 \pm 2.2$ & $303.07 \pm 4.4$ & 13.30 \\
5 & $\mathrm{AOM}+2 \%$ Hizikia fusiforme diet & $245.05 \pm 3.8$ & $300.71 \pm 3.7$ & 13.13 \\
6 & $\mathrm{AOM}+6 \%$ H. fusiforme diet & $259.84 \pm 4.2$ & $315.17 \pm 4.3$ & 14.67 \\
\hline
\end{tabular}

AOM: Azoxymethane $15 \mathrm{mg} / \mathrm{kg}$, subcutaneous injection $(1 \mathrm{ml} / \mathrm{kg})$.

Laboratories Inc., San Francisco, CA, USA), and incubated with diaminobenzidine (DAB, Zymed Laboratories Inc.) as a substrate. After washing, slides were examined after being counterstained with Meyer's hematoxylin and washed with tap water. For the negative control, the primary antibody was replaced with phosphate-buffered saline. Finally, we counted proliferating tumor cells under microscopy.

Statistical analysis. Data are expressed as mean \pm standard error of the mean (SEM). Data were analyzed using a one-way analysis of variance (ANOVA), followed by Dunnett's $t$-test for multiple comparisons using SPSS software (Release 12.0. SPSS Inc., Chicago, IL, USA). Statistical significance was considered at $p<0.05$.

\section{Results}

Feeding the experimental diets containing $C$. fulvescens and $H$. fusiforme did not produce any toxicity. Histological examinations revealed no morphological evidence of fatty liver (data not shown). The body weights of animals in groups 1 and 2 (control groups) were not significantly greater than those in the experimental groups (Table III) that received s.c. injections of $\mathrm{AOM}$ at $15 \mathrm{mg} / \mathrm{kg}$ body weight once a week for 2 weeks to investigate the formation of $\mathrm{ACF}$ in the colon. H\&E staining revealed significant histopathological changes in the colonic tissues of AOM-treated rats. We found histological abnormalities such as ACF including dysplasia and hyperplasia, abnormally shaped lumens and elongated nuclei in the colonic mucosa of the treated control group (group 2), but these findings were significantly $(p<0.05)$ less frequent in the experimental groups (groups 3-6) (Figure 2). These results demonstrate that $C$. fulvescens and $H$. fusiforme suppress dysplastic cell proliferation in the colonic tissues of AOM-treated rats.

The incidence and number of colorectal tumors after 11 weeks are listed in Table IV. In group 1 (untreated control), no colonic tumors were found. However, group 2 (treated control), colonic tissues were found to contain $58 \mathrm{ACF}$ (Figure 3). In the dose-response study, experimental $C$. fulvescens and $H$. fusiforme diets reduced the incidence of ACF formation $(p<0.05)$ in groups 3 and 4 , whereas the occurrence of ACF was significantly $(p<0.001)$ lower in groups 5 and 6 compared to the treated control. These findings suggest that $C$. fulvescens and $H$. fusiforme suppress ACF formation induced by AOM in the colon of rats.

To investigate the effects of dietary $C$. fulvescens and $H$. fusiforme, we used immunohistochemistry to analyze the expression of PCNA, a marker of tumor cell proliferation and apoptosis, at week 11. The colonic adenocarcinoma PCNA labeling index was lower $(p<0.05)$ in groups 4 and 5 , but in groups 3 and 4 more significantly $(p<0.001)$ lower than in the treated control group (Figure 5). 


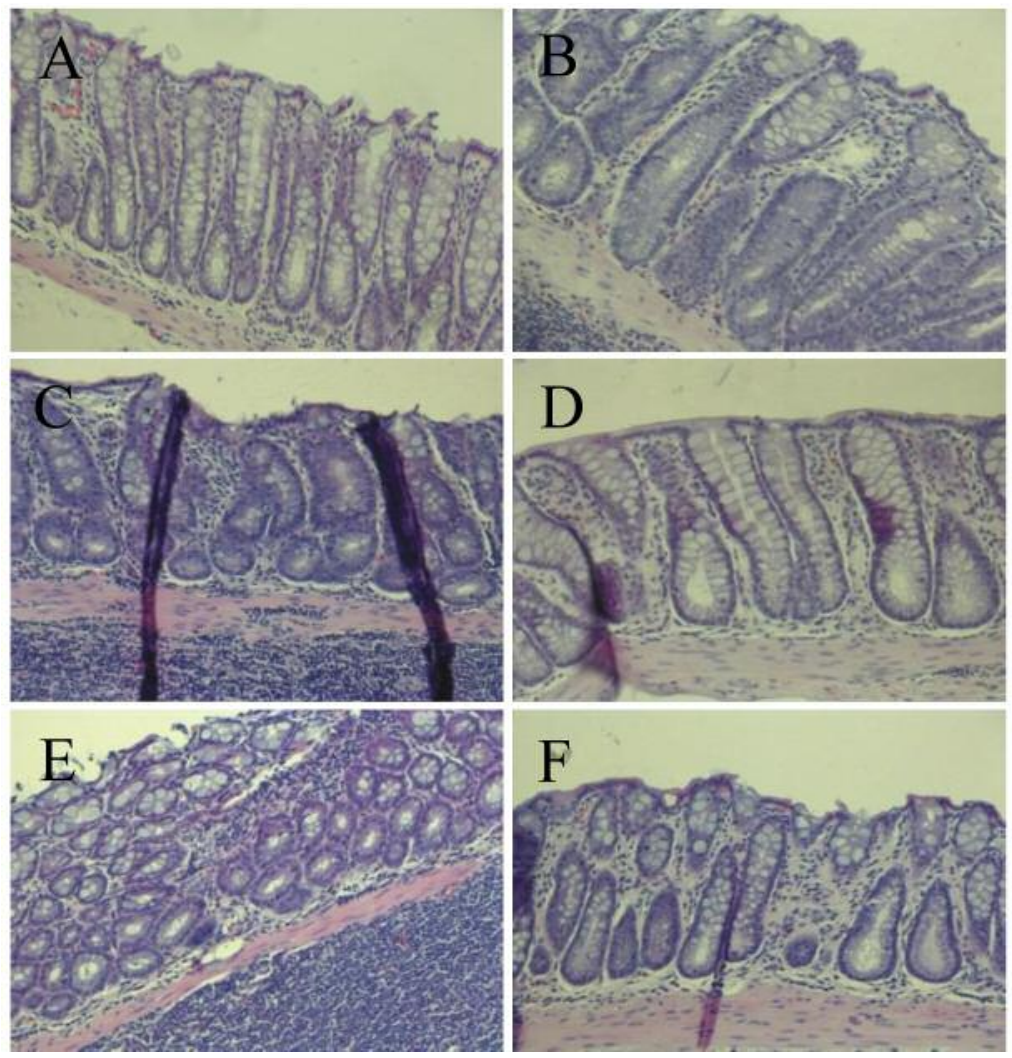

Figure 2. Histopathological examination of colonic tissues of F344 rats from group 1, saline + control diet (A); group 2, azoxymethane (AOM) + control diet $(B)$; group 3, AOM $+1 \%$ Capsosiphon fulvescens-supplemented diet $(C)$; group $4, A O M+2 \%$. fulvescens-supplemented diet $(D)$; group 5, AOM + 2\% Hizikia fusiforme-supplemented diet $(E)$; and group 6, AOM + 6\% H. fusiforme-supplemented diet $(F)$. Representative microscopic examination was performed with hematoxylin and eosin staining. Histological assessment showed the presence of aberrant crypt foci including dysplasia and hyperplasia, abnormally-shaped lumens and elongated nuclei in the colonic mucosa of the treated control group but a marked reduction in all experimental groups. Sections were examined at 200x magnification.

Table IV. Formation of azoxymethane (AOM)-induced aberrant crypt foci (ACF).

\begin{tabular}{|c|c|c|c|c|c|c|}
\hline \multirow[b]{2}{*}{ Group } & \multirow[b]{2}{*}{ Treatment } & \multicolumn{5}{|c|}{ Number of Aberrant Crypt Foci (ACF) } \\
\hline & & 1 & 2 & 3 & $\geq 4$ & Total \\
\hline 1 & Saline + control diet & 0 & 0 & 0 & 0 & 0 \\
\hline 2 & $\mathrm{AOM}+$ control diet & $22.43 \pm 2.6$ & $11.43 \pm 2.3$ & $13 \pm 3.6$ & $11 \pm 2.9$ & $57.86 \pm 2.9$ \\
\hline 3 & $\mathrm{AOM}+1 \%$ Capsosiphon fulvescens diet & $12.14 \pm 1.9$ & $5.57 \pm 2.0$ & $4.29 \pm 0.5$ & $7.45 \pm 1.1$ & $29.45 \pm 1.4 *$ \\
\hline 4 & $\mathrm{AOM}+2 \% C$. fulvescens $\operatorname{diet}$ & $11.71 \pm 1.4$ & $6.86 \pm 1.3$ & $4.14 \pm 0.7$ & $8.33 \pm 0.9$ & $31.05 \pm 1.1^{*}$ \\
\hline 5 & $\mathrm{AOM}+2 \%$ Hizikia fusiforme diet & $7.22 \pm 0.9$ & $4.88 \pm 0.5$ & $4.11 \pm 1.3$ & $4.97 \pm 0.3$ & $21.18 \pm 0.8 * *$ \\
\hline 6 & $\mathrm{AOM}+6 \% H$. fusiforme diet & $6.57 \pm 1.0$ & $4.33 \pm 0.7$ & $3.43 \pm 0.9$ & $6.17 \pm 1.4$ & $20.5 \pm 1.0 * *$ \\
\hline
\end{tabular}

AOM given at $15 \mathrm{mg} / \mathrm{kg}$, subcutaneous injection $(1 \mathrm{ml} / \mathrm{kg})$. Data are represented as mean \pm standard error of the mean. Asterisks indicate values significantly different from those in group 2 : $* p<0.05$ and $* * p<0.01$.

\section{Discussion}

Seaweeds are rich in bioactive substances that may be useful in treating a wide spectrum of diseases. Seaweeds contain health-promoting compounds such as phytochemicals, soluble dietary fibers, lipids, peptides, and minerals that hold potential as dietary supplements and that may reduce the risk of cancer $(16,17)$. Moreover, macroalgae have been used as food supplements, particularly in Japan, China, and Korea (18). The long life expectancy of Japanese people has been 

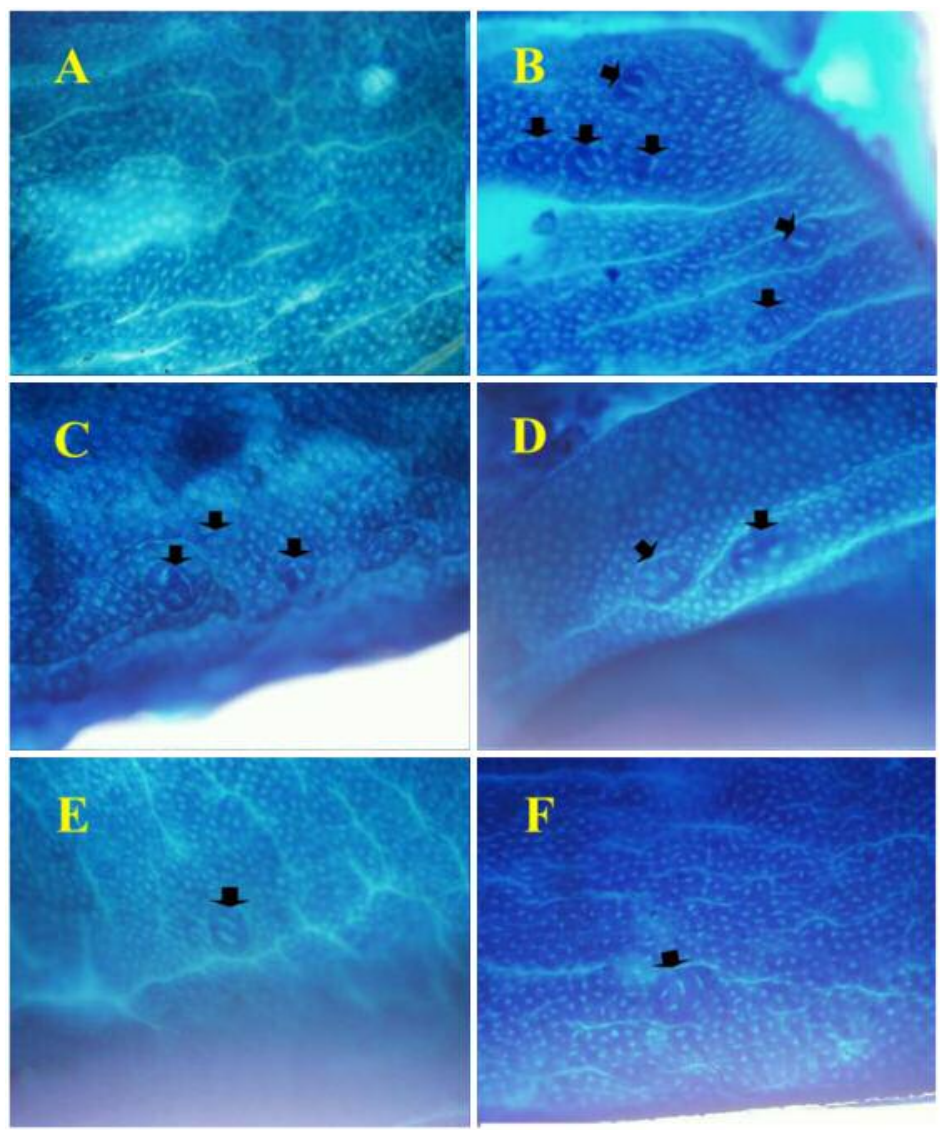

Figure 3. Histopathological sections, stained with methylene blue to identify crypts in the colonic tissues of F33 rats, and examined at 200x magnification. In group 1, we did not find formation of any aberrant crypt foci (ACF), while group 2 had the highest number of ACF; with groups 3-6 having significantly fewer crypts after dietary supplementation with different doses of Capsosiphon fulvescens (1 or 2\%) or Hizikia fusiforme (2 and 6\%), respectively. Arrows indicate ACF.

partly attributed to their dietary habits, including the regular consumption of seaweed (17).

Our experimental data suggest that $C$. fulvescens and $H$. fusiforme are effective chemopreventive agents for CRC. These chemopreventive effects may be due to the high levels of minerals such as $\mathrm{Na}, \mathrm{Mg}, \mathrm{K}, \mathrm{Ca}$, and $\mathrm{Fe}$ in both algae (15). AOM has the potential to induce colonic carcinomas in rats by promoting ACF formation. Carcinogenesis is conventionally defined by three stages: initiation, promotion, and progression $(19,20)$. During the initiation stage, normal cells experience DNA damage $(21,22)$. During the second stage, promotion, the initiated cells affect normal cells, forming preneoplastic lesions (23). Finally, in the progression stage, malignant tumors develop, leading to metastasis (24).

In the present study, we demonstrated that dietary administration of $C$. fulvescens and $H$. fusiforme caused no significant difference in body weight in groups 3-6 over the experimental period compared with that in groups 1 (untreated control group) and 2 (treated control group). Additionally, there was no significant difference in feed intake between any of the experimental groups. This suggests that $C$. fulvescens and $H$. fusiforme may both have beneficial effects (14) (Table III).

H\&E staining of colonic tissues was carried out for histological analyses. Throughout the colonic mucosa of the AOM-treated rats, we observed abnormalities, consistent with molecular aberrations in the treated control group (group 2), but such histological abnormalities were not found in the experimental groups (Figure 2). This demonstrates that dietary $C$. fulvescens and $H$. fusiforme have chemopreventive effects.

The ACF assay evaluates crypts with abnormal morphology, such as those found in group 2. In groups 3-6, dietary administration of $C$. fulvescens and $H$. fusiforme resulted in significantly less ACF formation than in the treated control group (Figure 3), suggesting that these agents counteract the carcinogenic activities of AOM. 

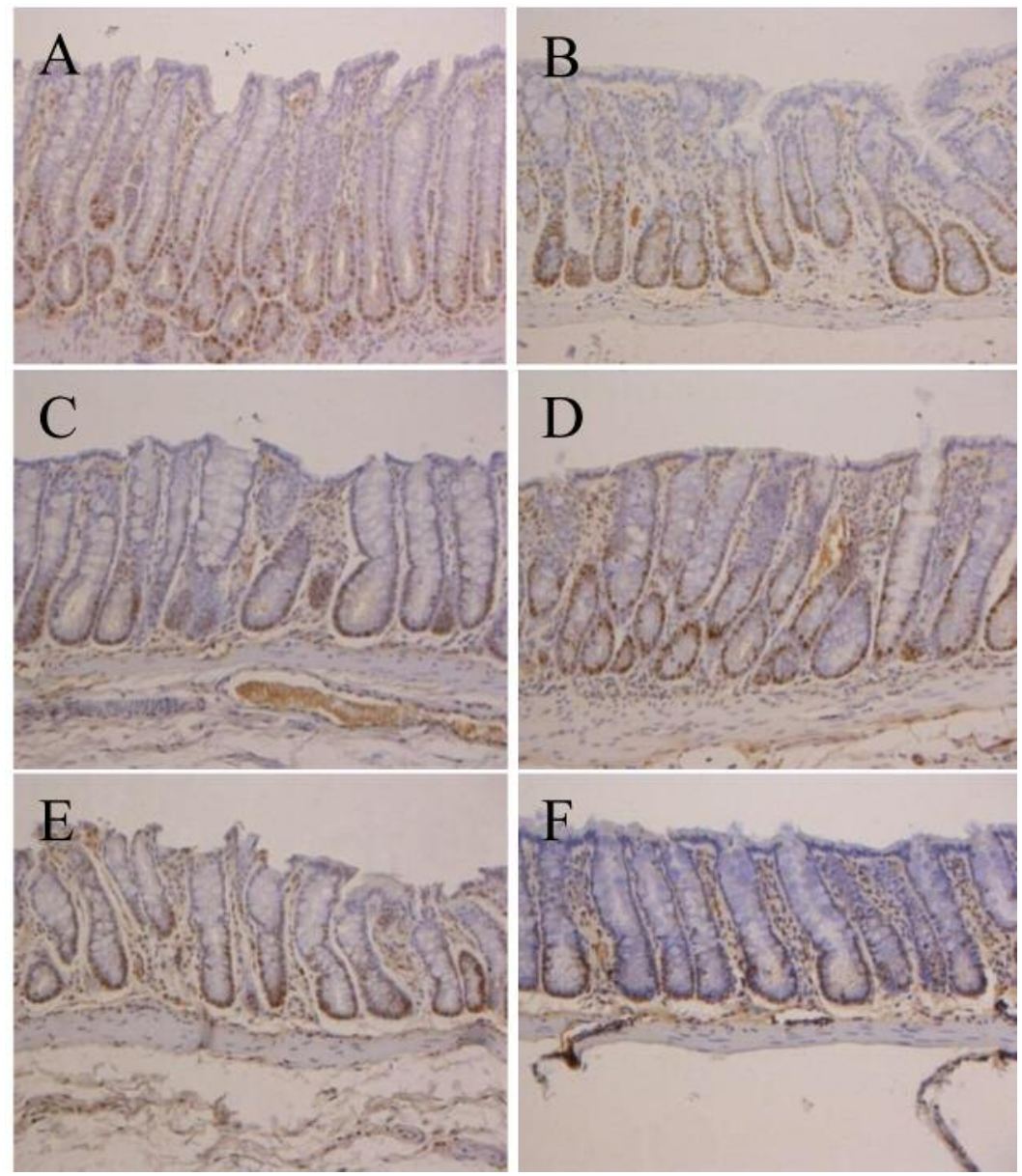

Figure 4. Immunohistochemical analysis of proliferating cell nuclear antigen (PCNA) in colonic tissue of F344 rats from groups 1-6. In group 1, we observed PCNA-negative cells (blue color); in group 2, we found PCNA-positive cells (brown color); but experimental groups 3-6 had fewer PCNA-positive cells than the treated controls (group 2). Colonic tissues were examined at 200x magnification.

Dietary administration of $C$. fulvescens and $H$. fusiforme prevented AOM-induced colorectal proliferative lesions in rats (Figure 4). Experimental groups exhibited pronounced suppression of cell proliferation compared with the treated control group. Groups 3-6 had significantly lower CRC PCNA labeling indices in comparison with that of group 2, suggesting that $C$. fulvescens and $H$. fusiforme might both modulate cell proliferation (Figure 5).

Although the mechanism of inhibition of AOM-induced ACF formation in rats by $C$. fulvescens and $H$. fusiforme has not been established, one possibility is through interference with the cytochrome P450 2E1 (CYP2E1) pathway, due to their potent antioxidant activity $(14,15,25-27)$. It has been suggested that suppression of CYP2E1 inhibits chemical carcinogenesis $(4,28)$. In vivo, AOM is largely metabolized by isoform CYP2E1 $(4,29,30)$. A previous study established that AOM-induced ACF formation was significantly lower in Cyp2e1, knockout mice (29). In the present study, we

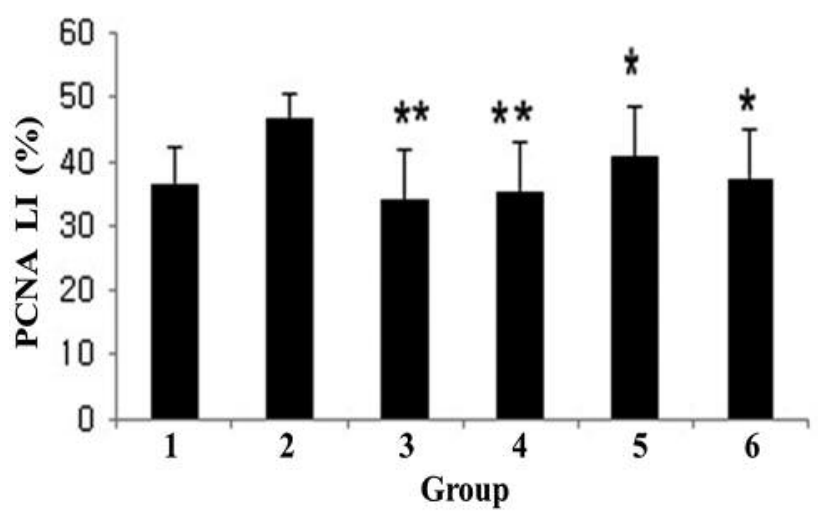

Figure 5. Proliferating cell nuclear antigen (PCNA) labeling index (\%) of colonic mucosa in 5344 rats. Group 1 was the untreated control, group 2 had the highest index, while groups 3-6 demonstrated the significant inhibitory effect of dietary Capsosiphon fulvescens $(* * p<0.01)$ and Hizikia fusiforme $(* p<0.05)$ on PCNA labeling index compared to group 2. The data represent the mean \pm standard error of the mean. 
demonstrated that dietary $C$. fulvescens and $H$. fusiforme both suppressed formation of AOM-induced ACF in rats.

In conclusion, many chemopreventive agents have been shown to exhibit inhibitory effects on cancer in preliminary studies. Our results clearly revealed the potential benefits of $C$. fulvescens and H. fusiforme at inhibiting ACF formation. However, the optimal dose for an anticancer effect needs to be identified. Further studies on determination of the optimum dose of $C$. fulvescens and $H$.fusiforme in inhibiting $\mathrm{ACF}$ formation are required.

\section{Conflicts of interest}

The Authors declare no conflict of interest in regard to this study.

\section{Acknowledgements}

This work was supported by the Korea Health Technology R\&D Project through the Korea Health Industry Development Institute (KHIDI), which is funded by the Ministry of Health \& Welfare, Republic of Korea (grant number: HI15C0001).

\section{References}

1 Haggar FA and Boushey RP: Colorectal cancer epidemiology: incidence, mortality, survival, and risk factors. Clin Colon Rectal Surg 22: 191-197, 2009.

2 Fung KY, Cosgrove L, Lockett T, Head R and Topping DL: A review of the potential mechanisms for the lowering of colorectal oncogenesis by butyrate. Br J Nutr 108: 820-831, 2012.

3 Mármol I, Sánchez-de-Diego C, Pradilla Dieste A, Cerrada E and Rodriguez Yoldi MJ: Colorectal carcinoma: a general overview and future perspectives in colorectal cancer. Int J Mol Sci 18: 197, 2017.

4 Chen J and Huang XF: The signal pathways in azoxymethaneinduced colon cancer and preventive implications. Cancer Biol Ther 8: 1313-1317, 2009.

5 Armaghany T, Wilson JD, Chu Q and Mills G: Genetic alterations in colorectal cancer. Gastrointest Cancer Res 5: 19, 2012.

6 Murillo G, Kosmeder JW, Pezzuto JM and Mehta RG: Deguelin suppresses the formation of carcinogen-induced aberrant crypt foci in the colon of CF-1 mice. Int J Cancer 104: 7-11, 2003.

7 Neufert C, Becker C and Neurath MF: An inducible mouse model of colon carcinogenesis for the analysis of sporadic and inflammation-driven tumor progression. Nat Protoc 2: 19982004, 2007.

8 Poulin EJ, Shen J, Gierut JJ and Haigis KM: Pathology and molecular pathology of colorectal cancer. Pathology and Epidemiology of Cancer. Springer Cham: 409-446, 2017.

9 Hao X, Xiao H, Ju J, Lee MJ, Lambert JD and Yang CS: Green tea polyphenols inhibit colorectal tumorigenesis in azoxymethanetreated F344 Rats. Nutr Cancer 69: 623-631, 2017.

10 De Robertis M, Arigoni M, Loiacono L, Riccardo F, Calogero RA, Feodorova Y, Tashkova D, Belovejdov V, Sarafian V, Cavallo F and Signori E: Novel insights into Notum and glypicans regulation in colorectal cancer. Oncotarget 6: 41237, 2015.

11 McLellan EA and Bird RP: Aberrant crypts: potential preneoplastic lesions in the murine colon. Cancer Res 48: 6187-6192, 1988.
12 Kensara OA, El-Shemi AG, Mohamed AM, Refaat B, Idris S and Ahmad J: Thymoquinone subdues tumor growth and potentiates the chemopreventive effect of 5-fluorouracil on the early stages of colorectal carcinogenesis in rats. Drug Des Dev Ther 10: 2239, 2016.

13 Islam MN, Choi SH, Moon HE, Park JJ, Jung HA, Woo MH, Woo HC and Choi JS: The inhibitory activities of the edible green alga Capsosiphon fulvescens on rat lens aldose reductase and advanced glycation end products formation. Eur J Nutr 53: 233-242, 2014

14 Tong T, Ko DO, Kim BS, Ham KS and Kang SG: Beneficial effect of seaweed on high-fat diet-induced oxidative stress and insulin resistance in rats. Food Sci Biotechnol 24: 2185-2191, 2015.

15 Tong T, Zhang C, Ko DO, Kim SB, Jung KJ and Kang SG: Effects of the addition of Hizikia fusiforme, Capsosiphon fulvescens, and Undaria pinnatifida sporophyll on antioxidant and inhibitory potential against enzymes related to type 2 diabetes of vegetable extract. Korean J Food Preserv 21: 460-467, 2014.

16 Matos J, Cardoso C, Bandarra NM and Afonso C: Microalgae as a healthy ingredient for functional food: A review. Food Funct 8: 2672-2685, 2017.

17 Cardoso SM, Pereira OR, Seca AM, Pinto DC and Silva A: Seaweeds as preventive agents for cardiovascular diseases: From nutrients to functional foods. Mar Drugs 13: 6838-6865, 2015.

18 Jibri SM, Jakada BH, Umar HY and Ahmad TA: Importance of some algal species as a source of food and supplement. Int J Curr Microbiol Appl Sci 5: 186-193, 2016.

19 Martín MA, Goya L and Ramos S: Preventive effects of cocoa and cocoa antioxidants in colon cancer. Diseases 4: 6, 2016.

20 Pritchard CC and Grady WM: Colorectal cancer molecular biology moves into clinical practice. Gut 4: 116-129, 2011.

$21 \mathrm{Kim} \mathrm{J}, \mathrm{Ng} \mathrm{J}$, Arozulllah A, Ewing R, Llor X, Carroll RE and Benya RV: Aberrant crypt focus size predicts distal polyp histopathology. Cancer Epidemiol Biomarkers Prev 17: 1155$1162,2008$.

22 Fearon ER and Vogelstein B: A genetic model for colorectal tumorigenesis. Cell 61: 759-767, 1990.

23 Willis S, Sunkara R, Willis Z, Smith L, Hester F, Reid HM, Patel P, McCollum M, Shackelford L, Onwasigwe E and Walker LT: Chemopreventive potential of select herbal teas and spices on azoxymethane-induced aberrant crypt foci in Fisher 344 male rats. Food Nutr Sci 8: 348, 2017.

24 Cooper GM: The Cell: A Molecular Approach, Second Edition. Sunderland, MA, USA, 2000.

$25 \mathrm{Lu} \mathrm{Y}$ and Cederbaum AI: CYP2E1 and oxidative liver injury by alcohol. Free Radic Biol Med 44: 723-738, 2008.

26 Aoi W, Naito Y, Takagi T, Kokura S, Mizushima K, Takanami Y, Kawai Y, Tanimura Y, Hung LP, Koyama R and Ichikawa H: Regular exercise reduces colon tumorigenesis associated with suppression of iNOS. Biochem biophys Res Commun 399: 1419, 2010.

27 Chiou YS, Tsai ML, Nagabhushanam K, Wang YJ, Wu CH, Ho $\mathrm{CT}$ and Pan MH: Pterostilbene is more potent than resveratrol in preventing azoxymethane (AOM)-induced colon tumorigenesis via activation of the NF-E2-related factor 2 (Nrf2)-mediated antioxidant signaling pathway. J Agric Food Chem 59: 27252733,2011 
28 Brady JF, Xiao F, Wang MH, Li Y, Ning SM, Gapac JM and Yang CS: Effects of disulfiram on hepatic P450IIE1, other microsomal enzymes, and hepatotoxicity in rats. Toxicol Appl pharmacol 108: 366-373, 1991.

29 Sohn OS, Fiala ES, Requeijo SP, Weisburger JH and Gonzalez FJ: Differential effects of CYP2E1 status on the metabolic activation of the colon carcinogens azoxymethane and methylazoxymethanol. Cancer Res 61: 8435-8440, 2001.
30 Shimpo K, Chihara T, Beppu H, Ida C, Kaneko T, Hoshino M and Kuzuya $\mathrm{H}$ : Inhibition of azoxymethane-induced DNA adduct formation by Aloe arborescens var. natalensis. Asian Pac J Cancer Prev 4: 247-252, 2003.

Received September 21, 2017 Revised October 21, 2017 Accepted October 26, 2017 